\title{
How Does Mucorales Benefit from the Dysregulated Iron Homeostasis During SARS-CoV-2 Infection?
}

\author{
Nata Pratama Hardjo Lugito (1) - Cucunawangsih Cucunawangsih
}

Received: 8 June 2021 / Accepted: 25 September 2021/Published online: 8 October 2021

(C) The Author(s), under exclusive licence to Springer Nature B.V. 2021

\begin{abstract}
Mucorales is the cause of mucormycosis, an emerging opportunistic infection in the era of coronavirus disease 2019 (COVID-19) pandemic. Condition of hyperglycemia, diabetes mellitus, and acidosis; dysregulated iron homeostasis in the form of hyperferritinemic syndrome, and high concentration of iron in circulation; and endothelial injury related to abundance glucose regulated protein 78 (GRP78), which are present in severe COVID-19, could favor Mucorales infection. In this short communication, we summarized how the dysregulated iron homeostasis in severe acute respiratory syndrome coronavirus-2 (SARS-CoV-2) infection benefits Mucorales.
\end{abstract}

Keywords Mucorales · Iron homeostasis · SARSCoV-2

Handling Editor: Ferry Hagen.

\footnotetext{
N. P. H. Lugito ( $\square)$

Department of Internal Medicine, Faculty of Medicine, Pelita Harapan University, Tangerang, Banten, Indonesia 15811

e-mail: nata.lugito@uph.edu

C. Cucunawangsih

Department of Microbiology, Faculty of Medicine, Pelita

Harapan University, Tangerang, Banten, Indonesia 15811
}

Mucormycosis is an emerging infection in the era of COVID-19 pandemic, as it shares the same risk factors with severe COVID-19 which are uncontrolled diabetes mellitus (DM) the use of corticosteroids as treatment of severe or critical COVID-19, and excessive overuse of corticosteroids to treat COVID-19 [1-3]. A recent review of 41 COVID-19 patients with mucormycosis showed that $39 \%$ was already suffering from mucormycosis at admission, $67 \%$ had uncontrolable DM, 44\% was in diabetic ketoacidosis (DKA) state at admission, 98\% received systemic corticosteroids, and in-hospital mortality rate was $49 \%$ [2]. The most frequent species found was Rhizopus spp., followed by Lichtheimia spp., and Mucor spp. The review showed that the pathophysiology of mucormycosis could be associated to hyperglycemia, alteration in iron metabolism in the form of hyperferritinemic syndrome and high concentration of iron in circulation, endothelial injury related to glucose regulated protein 78 (GRP78) that were pathognomonic findings in severe COVID-19 [2]. Here we describe the potential mechanism on how Mucorales benefits from the dysregulated iron homeostasis in SARS-CoV-2 infection.

Mucorales are fungi within the subphylum Mucormycotina of the phylum Mucoromycota, and a few of fungi from this order can cause mucormycosis [4]. The most common cause of mucormycosis are Rhizopus arrhizus and R. microsporus that account for $57 \%$ of all cases. The genus Rhizomucor was the 
cause of outbreaks related to contaminated air while transmission by direct contact were related to Lichtheimia spp. and Mucor circinelloides [5, 6]. Mucormycosis is classified according to the location of infection, which could be pulmonary, rhinocerebral, rhinoorbital, gastrointestinal, cutaneous, or disseminated, and some uncommon infection such as osteomyelitis, kidney, peritonitis, and endocarditis [5]. Devastating consequences of mucormycosis is caused by the rapid invasion of blood vessels, that further progressed to thrombosis and tissue necrosis [7, 8]. The characteristics of human pathogenic Mucorales associated with the aggressive nature of mucormycosis are its rapid growth, ability to tolerate high temperature, ability to acquire iron from their host, ability to attach on endothelial cell via specific receptors, and ability to down regulate host-immune genes thus escaping immune system $[8,9]$.

The ability of Mucorales to acquire iron from their host is important as they are unable to survive in irondeprived condition [7]. Mucorales has developed ways to acquire iron from their host via two mechanisms which are (1) siderophores and (2) high-affinity iron uptake [5]. Siderophores are iron chelators, that can be classified as (1) intrinsic siderophores, which are synthesized by the fungi, for example rhizoferrin, and (2) extrinsic siderophores, which are synthesized by other microorganisms and are called xenosiderophores [7]. Iron chelator such as deferoxamine, deferiprone, or deferasirox, is used in patients with increased risk of iron overload for example in end stage renal disease patients on renal replacement therapy or multiple transfusions patients. While deferiprone or deferasirox could not be used as xenosiderophores, deferoxamine that binds with iron from transferrin to form ferrioxamine that could function as xenosiderophore for Mucorales [7, 8, 10, 11]. Ferrioxamine then induced expression of Fob1 and Fob2 proteins on the fungal surface, where the iron is transported inside by the high-affinity iron uptake [11]. The high-affinity iron uptake mechanism is comprised of three proteins which are (1) Fre (a plasma membrane ferric reductase encoded by FRE genes) which reduce $\mathrm{Fe}^{3+}$ to $\mathrm{Fe}^{2+}$, (2) Fet3 is an iron transport multicopper ferrooxidase encoded by FET3 genes which oxidizes $\mathrm{Fe}^{2+}$ to $\mathrm{Fe}^{3+}$, and (3) Ftrl is a high affinity iron permease encoded by FTR 1 gene which transport $\mathrm{Fe}^{3+}$ inside the fungal cell $[12,13]$. Ftrl also facilitates transport of iron from heme or ferrioxamine [14]. There is a greater number of genes involved in siderophores and high-affinity iron uptake mechanism in the genome of the opportunistic pathogen Mucor indicus compared to other Mucorales. In the $M$. indicus genome, the rfs rhizoferrin biosynthesis gene, MirB-like siderophore permease encoding gene which are responsible for the siderophore pathways, FET3b and FET3c genes were duplicated. On the other hand, the two cheeseassociated species i.e. M. fuscus and M. lanceolatus had fewer number of genes involved in iron uptake in the genomes [15]. A review stated that the iron concentration in the environment regulates the expression of high-affinity iron uptake genes especially the FET3 and FTR 1 genes. Thus, it emphasizes the crucial role of the high-affinity iron uptake mechanism, associated with the susceptibility of mucormycosis in patients with unbalanced iron concentration [13] (Fig. 1).

Mucorales express spore coat homolog $(\mathrm{CotH})$ proteins to adhere to endothelial cells [7, 16]. The commonly isolated species in mucormycosis such as Rhizopus, Mucor, Rhizomucor, Cokeromyces, and Lichtheimia contained 3-7 CotH gene copies, while the rarely isolated species such as Mortierella and Apophysomyces only contained 1-2 gene copies. These findings suggest that the CotH-like genes are associated with Mucorales' ability to cause invasive disease [17]. Binding of CotH proteins to the host endothelial receptor glucose regulated protein 78 (GRP78) leads to fungal endocytosis [16, 18]. GRP78, a member of HSP70 family is a heat shock protein usually found in the endoplasmic reticulum (ER) of endothelial cells. GRP78 is a protein induced by glucose starvation and marker of ER stress [19]. In a condition of acidosis, elevated concentration of iron and glucose, GRP78 is overexpressed and released from ER of the endothelial cells to the surface where it interact with $\mathrm{CotH}$ proteins [3]. These conditions also lead to overexpression of CotH proteins in Mucorales [7]. A review stated that although the binding of $\mathrm{CotH}$ proteins and GRP78 is an important part of endothelial cells invasion by Mucorales, this binding does not play a role in the initial fungal adherence to endothelial cells [7].

Free iron is not available in human plasma because it is chelated to ferritin and lactoferrin [12]. In patients with acidosis and elevated concentration of glucose seen in diabetic ketoacidosis (DKA), the low blood $\mathrm{pH}$ destabilizes and dissociates iron from ferritin and 


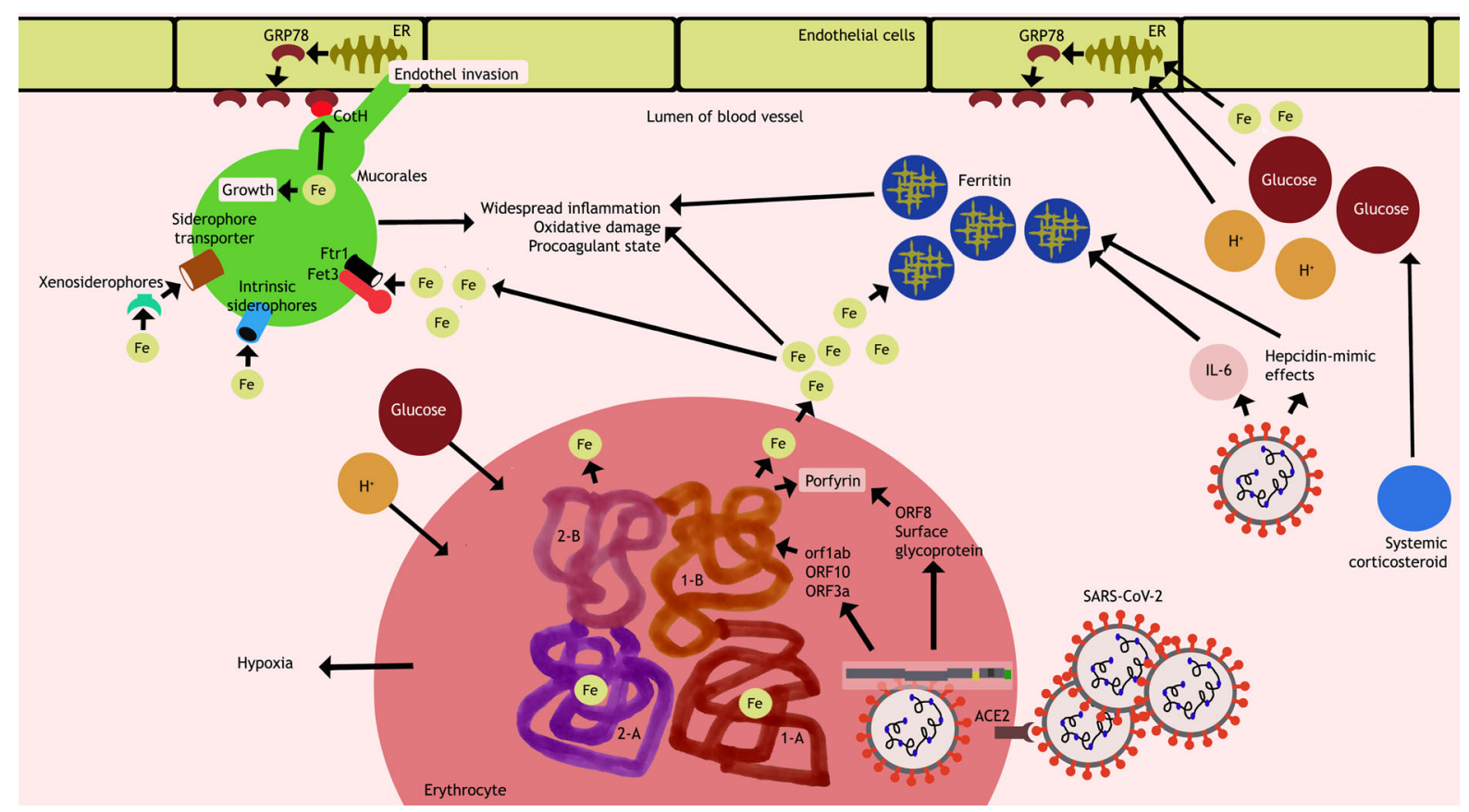

Fig. 1 Potential mechanism on how Mucorales benefits from the dysregulated iron homeostasis in SARS-CoV-2 infection. (A) SARS-CoV-2 proteins (orf1ab, ORF10, ORF3a) attack 1- $\beta$ chain of hemoglobin of erythrocyte and dissociate iron $(\mathrm{Fe})$ to circulation. Glucose and $\mathrm{H}^{+}$also dissociate $\mathrm{Fe}$ from hemoglobin. (B) SARS-CoV-2 causes IL-6 overexpression and has hepcidin-mimetic effects that increase ferritin level. High level of Fe chelates with ferritin, causing hyperferritinemia that result in widespread inflammation, oxidative damage and

lactoferrin, resulting in increased concentration of free ferric $\left(\mathrm{Fe}^{3+}\right)$ in plasma [20]. This increased concentration leads to uptake of free $\mathrm{Fe}^{3+}$ via high affinity iron uptake mechanism, providing iron that is needed for the growth of Mucorales [13]. Increased glucose and iron concentration also impair the phagocyte function such as phagocytosis and chemotaxis [19]. As stated previously, acidosis and increased glucose and iron concentration also induce overexpression of GRP78 and CotH which important for endothelial cells invasion by Mucorales [7, 18]. A study found that a ketone reductase system has been found in Rhizopus oryzae and might also contribute to its dissemination only under ketoacidotic condition such as DKA, and not under acidosis caused by other conditions. This study also found that sodium bicarbonate could reverse the effect of ketoacidosis and protected mice from mucormycosis [21]. All the above explains why diabetic patients especially DKA patients are susceptibility of to mucormycosis. The use of systemic procoagulant state. (C) Systemic corticosteroid causes increased serum glucose, and together with $\mathrm{H}^{+}$and $\mathrm{Fe}$ promote overexpression of GRP78, that binds to Mucorales' CotH to facilitate endothelial cells invasion. (D) Mucorales acquire Fe through high affinity iron uptake (Ftr1, Fet3), intrinsic siderophores, and xenosiderophores. Fe is essential for Mucorales growth and $\mathrm{CotH}$ overexpression to invade endothelial cells

corticosteroids could affect glucose homeostasis and also impair the phagocyte function making patients vulnerable to opportunistic mycoses including mucormycosis [2].

A study found that ORF1ab, ORF10, ORF3a proteins of SARS-CoV-2 coordinately attack the $1-\beta$ chain of hemoglobin then dissociate the iron to form the porphyrin and releasing iron in to circulation, the ORF8 protein and surface glycoprotein of SARSCoV-2 could form a complex with the resulted porphyrin. The loss of iron from hemoglobin disrupts the hemoglobin's ability to bind with oxygen, preventing oxygen delivery to body organs and causing hypoxia [22]. This explains the severe hypoxia that is not corrected with high oxygen therapy. The high free iron in the circulation then leads to widespread inflammation, including oxidative damage to the lung's tissue and alveolar macrophages [23]. The high iron level during severe inflammatory conditions will worsen inflammation and also induce a pro-coagulant 
state. The compensatory mechanism for the hemoglobin's loss of iron is by boosting ferritin production that caused hyperferritinemia [23]. This state of hyperferritinemia is the indicator of the "hyperferritinemic syndromes" which is associated with some inflammatory conditions [24]. It was observed that serum ferritin level above $300 \mu \mathrm{g} / \mathrm{l}$ was associated with COVID-19 severity and mortality [25]. Ferritin synthesis in COVID-19 was thought to be induced by inflammatory stimuli including cytokines, such as interleukin-6 (IL-6), where high IL-6 concentrations in COVID-19 patients was associated with severe disease [26]. The hepcidin-mimic effects of SARSCoV-2 might also contribute to increased ferritin level that is not related to the inflammatory state, and finally increase coagulopathy risk [27]. There has been no prospective study on the association between iron profile of COVID-19 patients with severity and mortality. So far there have only been retrospective studies, thus no definitive association could be drawn. The SARS-CoV-2 attack on the $1-\beta$ chain of hemoglobin would have resulted in high free iron levels in the serum of COVID-19 patients. A study on the association between serum iron level with severity and mortality of COVID-19 patients reported that $90 \%$ of patients had abnormally low serum iron levels, and that low serum iron on admission was associated with severity of the disease, but not associated with mortality of COVID-19 patients [28]. It could be plausible that the high free iron in the circulation has already depleted after being used in the widespread inflammation or stored in ferritin to compensate for hemoglobin's loss of iron.

In the presence of Mucorales in COVID-19 patients, the low iron serum level would activate siderophores and high-affinity iron uptake of Mucorales. These mechanisms would further deplete serum iron that was already low and worsen the hemoglobin disruption in COVID-19 patients, making the organ hypoxia in worse. The ferritin level would also increase to further compensate iron loss from hemoglobin, worsening the inflammatory state and its consequence such as coagulopathy.

Studies have found that GRP78 is overexpressed in numerous coronaviruses infection, such as Middle East Respiratory Syndrome coronavirus (MERS-CoV) and severe acute respiratory syndrome coronavirus (SARS-CoV) infections [29, 30], and that SARS-CoV infection induces ER stress [31]. A recent study found that GRP78 is associated with internalization of SARS-CoV-2 into host cells [32]. The GRP78 level is also found to be higher in the COVID-19 pneumonia patients compared to both healthy and COVID-19 patients without pneumonia [33]. In COVID-19 patients without pneumonia, the pulmonary endothelial cell ER stress caused by SARS-CoV-2 would increase GRP78 level and facilitate internalization of the virus, pulmonary endothelial cell dysfunction, pneumonia, and ARDS [34] In COVID-19 patients with mucormycosis, it is plausible that the CotH proteins of Mucorales would bind easily to the already overexpressed GRP78 and leads to the fungal endocytosis to endothelial cell.

Hyperglycemia complicated by DKA and medications with systemic corticosteroids which are frequent in many COVID-19 patients also added susceptibility of to mucormycosis [35]. Elevated blood glucose and DKA cause dissociation of iron from ferritin and lactoferrin, resulting in increased concentration of free ferric $\left(\mathrm{Fe}^{3+}\right)$ in plasma that is needed for Mucorales growth. Elevated blood glucose and DKA also lead to overexpression and release of GRP78 from ER of the endothelial cells to interact with Mucorales' CotH proteins. Systemic corticosteroids would affect glucose level and also impair the phagocyte function against mucorales' invasion.

We can conclude that the dysregulated iron homeostasis in SARS-CoV-2 infection caused by virus' attack on 1- $\beta$ chain of hemoglobin, resulting high serum iron concentration, overexpression of GRP78, and later hyperferritinemia. GRP78 abundance will facilitate Mucorales invasion of endothelial cell through binding with CotH proteins. Hyperferritinemia will lower serum iron as ferritin chelates free iron from serum. The low serum iron induces Mucorales to acquire iron through siderophores and high-affinity iron uptake mechanisms, resulting in overgrowth of Mucorales with devastating and often fatal consequences. There is currently no data on the iron status of COVID-19 patients with mucormycosis, thus data of iron status in these patients would give us a better picture in understanding the role of iron in the Mucorales' pathogenesis in COVID-19 patients. 


\section{References}

1. Garg D, Muthu V, Sehgal IS, Ramachandran R, Kaur H, Bhalla A, Puri GD, Chakrabarti A, Agarwal R. Coronavirus disease (Covid-19) associated mucormycosis (CAM): case report and systematic review of literature. Mycopathologia. 2021;186:289-98. https://doi.org/10.1007/s11046-02100528-2.

2. John TM, Jacob CN, Kontoyiannis DP. When uncontrolled diabetes mellitus and severe COVID-19 converge: the perfect storm for mucormycosis. J Fungi. 2021;7:298. https:// doi.org/10.3390/jof7040298.

3. Gupta A, Sharma A, Chakrabarti A. The emergence of postCOVID-19 mucormycosis in India: can we prevent it? Indian J Ophthalmol. 2021;69(7):1645-7. https://doi.org/ 10.4103/ijo.IJO_1392_21 (PMID: 34146000).

4. Spatafora JW, Chang Y, Benny GL, Lazarus K, Smith ME, Berbee ML, Bonito G, Corradi N, Grigoriev I, Gryganskyi A, James TY, O'Donnell K, Roberson RW, Taylor TN, Uehling J, Vilgalys R, White MM. A phylum-level phylogenetic classification of zygomycete fungi based on genome-scale data. Mycologia. 2016;108(5):1028-46.

5. Farmakiotis D, Kontoyiannis DP. Mucormycoses. Infect Dis Clin North Am. 2016;30:143-63.

6. Walther G, Wagner L, Kurzai O. Outbreaks of mucorales and the species involved. Mycopathologia. 2020;185:765-81. https://doi.org/10.1007/s11046-01900403-1.

7. George P, Constantinos T. Recent advances in the pathogenesis of mucormycoses. Clin Ther. 2018;40(6):894-902. https://doi.org/10.1016/j.clinthera.2018.03.009.

8. Petrikkos G, Skiada A, Lortholary O, Roilides E, Walsh TJ, Kontoyiannis DP. Epidemiology and clinical manifestations of mucormycosis. Clin Infect Dis. 2012;54:S23-34.

9. Lewis RE, Kontoyiannis DP. Epidemiology and treatment of mucormycosis. Future Microbiol. 2013;8:1163-75.

10. Liu M, Lin L, Gebremariam T, Luo G, Skory CD, French SW, Chou TF, Edwards JE, Ibrahim AS. Fob1 and Fob2 proteins are virulence determinants of Rhizopus oryzae via facilitating iron uptake from ferrioxamine. PLoS Pathog. 2015;11:e1004842.

11. Ibrahim AS, Edwards JE, Fu Y, Spellberg B. Deferiprone iron chelation as a novel therapy for experimental mucormycosis. J Antimicrob Chemother. 2006;58:1070-3.

12. Lax C, Pérez-Arques C, Navarro-Mendoza MI, Márquez JTC, Tahiri G, Pérez-Ruiz JA, Osorio-Concepción M, Murcia-Flores L, Navarro E, Garre V, Nicolás FE. Genes, pathways, and mechanisms involved in the virulence of mucorales. Genes. 2020;11:317. https://doi.org/10.3390/ genes 11030317.

13. Navarro-Mendoza MI, Pérez-Arques C, Murcia L, Martínez-García P, Lax C, Sanchis M, Capilla J, Nicolás FE, Garre V. Components of a new gene family of ferroxidases involved in virulence are functionally specialized in fungal dimorphism. Sci Rep. 2018;8:7660. https://doi.org/10.1038/ s41598-018-26051-x.

14. Ibrahim AS, Gebremariam T, Lin L, Luo G, Husseiny MI, Skory CD, Fu Y, French SW, Edwards JE Jr, Spellberg B. The high affinity iron permease is a key virulence factor required for Rhizopus oryzae pathogenesis: FTR1 and mucormycosis virulence. Mol Microbiol. 2010;77:587-604.

15. Lebreton A, Corre E, Jany J-L, Brillet-Guéguen L, PèrezArques C, Garre V, Monsoor M, Debuchy R, Meur CL, Coton E, Barbier G, Meslet-Cladière L. Comparative genomics applied to Mucor species with different lifestyles. Genomics. 2020;21:135. https://doi.org/10.1186/s12864019-6256-2.

16. Gebremariam T, Liu M, Luo G, Bruno V, Phan QT, Waring AJ, Edwards JE Jr, Filler SG, Yeaman MR, Ibrahim AS. CotH3 mediates fungal invasion of host cells during mucormycosis. J Clin Invest. 2014;124:237-50.

17. Chibucos MC, Soliman S, Gebremariam T, Lee $H$, Daugherty S, Orvis J, Shetty AC, Crabtree J, Hazen TH, Etienne KA, Kumari P, O'Connor TD, Rasko DA, Filler SG, Fraser CM, Lockhart SR, Skory CD, Ibrahim AS, Bruno VM. An integrated genomic and transcriptomic survey of mucormycosis-causing fungi. Nat Commun. 2016;7:12218. https://doi.org/10.1038/ncomms12218.

18. Liu M, Spellberg B, Phan QT, Fu Y, Fu Y, Lee AS, Edwards JE Jr, Filler SG, Ibrahim AS. The endothelial cell receptor GRP78 is required for mucormycosis pathogenesis in diabetic mice. J Clin Invest. 2010;120:1914-24.

19. Ibrahim AS. Host cell invasion in mucormycosis: role of iron. Curr Opin Microbiol. 2011;14(4):406-11. https://doi. org/10.1016/j.mib.2011.07.004.

20. Gebremariam T, Lin L, Liu M, Kontoyiannis DP, French S, Edwards JE, Filler SG, Ibrahim AS. Bicarbonate correction of ketoacidosis alters host-pathogen interactions and alleviates mucormycosis. J Clin Investig. 2016;126:2280-94.

21. Gebremariam T, Lin L, Liu M, Kontoyiannis DP, French S, Edwards JE Jr, Filler SG, Ibrahim AS. Bicarbonate correction of ketoacidosis alters host-pathogen interactions and alleviates mucormycosis. J Clin Invest. 2016;126:2280-94.

22. Liu W, Li H. COVID-19: attacks the 1-beta chain of hemoglobin and captures the porphyrin to inhibit human heme metabolism. ChemRxiv. 2020. https://doi.org/10. 26434/chemrxiv.11938173.v8

23. Habib HM, Ibrahim S, Zaim A, Ibrahim WH. The role of iron in the pathogenesis of COVID-19 and possible treatment with lactoferrin and other iron chelators. Biomed Pharmacother. 2021;136: 111228. https://doi.org/10.1016/j. biopha.2021.111228.

24. Edeas M, Saleh J, Peyssonnaux C. Iron: innocent bystander or vicious culprit in COVID-19 pathogenesis? Int J Infect Dis. 2020;97:303-5. https://doi.org/10.1016/j.ijid.2020.05. 110.

25. Colafrancesco S, Alessandri C, Conti F. Priori R COVID-19 gone bad: a new character in the spectrum of the hyperferritinemic syndrome? Autoimmun Rev. 2020;19(7): 102573. https://doi.org/10.1016/j.autrev.2020.102573.

26. Gomez-Pastora J, Weigand M, Kim J, Wu X, Strayer J, Palmer AF, Zborowski M, Yazer M, Chalmers JJ. Hyperferritinemia in critically ill COVID-19 patients-is ferritin the product of inflammation or a pathogenic mediator? Clin Chim Acta. 2020;509:249-51.

27. Cavezzi A, Troiani E, Corrao S. COVID-19: hemoglobin, iron, and hypoxia beyond inflammation. A narrative review. Clin Pract. 2020;10(2):24-30. https://doi.org/10.4081/cp. 2020.1271. 
28. Zhao K, Huang J, Dai D, Feng Y, Liu L, Nie S. Serum iron level as a potential predictor of coronavirus disease 2019 severity and mortality: a retrospective study. Open Forum Infect Dis. 2020;7(7):ofaa250. https://doi.org/10.1093/ofid/ ofaa250.

29. Chu H, Chan CM, Zhang X, Wang Y, Yuan S, Zhou J, AuYeung RK, Sze K-H, Yang D, Shuai H, Hou Y, Li C, Zhao X, Poon VK, Leung SP, Yeung M-L, Yan J, Lu G, Jin D-Y, Gao GF, Chan JF-W, Yuen K-Y. Middle East respiratory syndrome coronavirus and bat coronavirus HKU9 both can utilize GRP78 for attachment onto host cells. J Biol Chem. 2018;293(30):11709-26. https://doi.org/10.1074/jbc. RA118.001897.

30. Chan CP, Siu KL, Chin KT, Yuen KY, Zheng B, Jin DY. Modulation of the unfolded protein response by the severe acute respiratory syndrome coronavirus spike protein. J Virol. 2006;80(18):9279-87.

31. Versteeg GA, van de Nes PS, Bredenbeek PJ, Spaan WJM. The coronavirus spike protein induces endoplasmic reticulum stress and upregulation of intracellular chemokine mRNA concentrations. J Virol. 2007;81:10981-90.

32. Ibrahim IM, Abdelmalek DH, Elshahat ME, Elfiky AA. COVID-19 spike-host cell receptor GRP78 binding site prediction. J Inf Secur. 2020;80:554-62.
33. Palmeira A, Sousa E, Köseler A, Sabirli R, Gören T, Türkçüer I, Kurt Ö, Pinto MM, Vasconcelos MH. Preliminary virtual screening studies to identify GRP78 inhibitors which may interfere with SARS-CoV-2 infection. Pharmaceuticals (Basel). 2020;13:132.

34. Sabirli R, Köseler A, Gören T, Türkçüer I, Kurt Ö. High GRP78 levels in Covid-19 infection: a case-control study. Life Sci. 2021;265: 118781. https://doi.org/10.1016/j.lfs. 2020.118781.

35. Ahmadikia K, Hashemi SJ, Khodavaisy S, Getso MI, Alijani N, Badali H, Mirhendi H, Salehi M, Tabari A, Ardehali MM, Kord M, Roilides E, Rezaie S. The double-edged sword of systemic corticosteroid therapy in viral pneumonia: a case report and comparative review of influenza-associated mucormycosis versus COVID-19 associated mucormycosis. Mycoses. 2021;00:1-11. https://doi.org/10. 1111/myc. 13256 .

Publisher's Note Springer Nature remains neutral with regard to jurisdictional claims in published maps and institutional affiliations. 